\title{
Fermentative degradation of monohydroxybenzoates by defined syntrophic cocultures
}

\author{
Andreas Tschech* and Bernhard Schink ** \\ Fakultät für Biologie, Universität Konstanz, Postfach 5560, D-7750 Konstanz, Federal Republic of Germany
}

\begin{abstract}
From anaerobic freshwater enrichment cultures with 3-hydroxybenzoate as sole substrate, a slightly curved rod-shaped bacterium was isolated in coculture with $D e$ sulfovibrio vulgaris as hydrogen scavenger. The new isolate degraded only 3-hydroxybenzoate or benzoate, and depended on syntrophic cooperation with a hydrogenoxidizing methanogen or sulfate reducer. 3-Hydroxybenzoate was degraded via reductive dehydroxylation to benzoate. With 2-hydroxybenzoate (salicylate), short coccoid rods were enriched from anaerobic freshwater mud samples, and were isolated in defined coculture with $D$. vulgaris. This isolate also fermented 3-hydroxybenzoate or benzoate in obligate syntrophy with a hydrogen-oxidizing anaerobe. The new isolates were both Gram-negative, non-sporeforming strict anaerobes. They fermented hydroxybenzoate or benzoate to acetate, $\mathrm{CO}_{2}$, and, presumably, hydrogen which was oxidized by the syntrophic partner organism. With hydroxybenzoates, but not with benzoate, Acetobacterium woodii could also serve as syntrophic partner. Other substrates such as sugars, alcohols, fatty or amino acids were not fermented. External electron acceptors such as sulfate, sulfite, nitrate, or fumarate were not reduced. In enrichment cultures with 4-hydroxybenzoate, decarboxylation to phenol was the initial step in degradation which finally led to acetate, methane and $\mathrm{CO}_{2}$.
\end{abstract}

Key words: Anaerobic benzoate degradation - Hydroxybenzoates - Aromatic compounds - Interspecies hydrogen transfer - Reductive dehydroxylation

Methanogenic degradation of aromatic compounds was first reported by Tarvin and Buswell (1934). Research mainly focussed on degradation of benzoate as a model substrate by photosynthetic, nitrate-reducing, or sulfate-reducing bacteria, as well as by undefined methanogenic enrichment cultures (Evans 1977; Young 1984). A defined methanogenic coculture, Syntrophus buswellii, was isolated recently which ferments benzoate to acetate, $\mathrm{CO}_{2}$ and methane (Mountfort and Bryant 1982; Mountfort et al. 1984). A further defined coculture of this type was isolated from an enrichment culture with 3-chlorobenzoate as substrate (Shelton and

* Present address and offprint requests to: Angewandte Mikrobiologie, Universität Ulm, Oberer Eselsberg M23, D-7900 Ulm, Federal Republic of Germany

** Present address: Fachbereich Biologie, D-3550 Marburg, Federal Republic of Germany
Tiedje 1984). Methanogenic degradation of hydroxylated and methoxylated benzoates and phenols was, so far, mainly studied with undefined enrichment cultures (Healy and Young 1979; Kaiser and Hanselmann 1982). Benzoates carrying three hydroxy groups can be fermented to acetate and $\mathrm{CO}_{2}$ by pure cultures of e.g. Pelobacter acidigallici (Schink and Pfennig 1982), and the same is true for trihydroxybenzenes. Resorcinol and resorcylic acids, with two hydroxy groups in meta-position to each other, are fermented to acetate and butyrate or acetate alone by defined cultures of strictly anaerobic bacteria; degradation does not always depend on a syntrophic cooperation with hydrogenscavenging anaerobes (Tschech and Schink 1985). Methanogenic degradation of catechol and hydroquinone proceeded in enrichment cultures via reductive dehydroxylation to phenol, and appeared to depend on syntrophic hydrogen oxidation (Szewzyk et al. 1985). Fermentative degradation of monohydroxybenzoates has not yet been studied in defined cultures. In the present paper, we describe two obligately syntrophic bacteria that degrade 2- or 3-hydroxybenzoate as well as benzoate to acetate, $\mathrm{CO}_{2}$, and $\mathrm{H}_{2}$. 3-Hydroxybenzoate is apparently degraded via benzoate after reductive elimination of the hydroxy group.

\section{Materials and methods}

\section{Sources of organisms}

Freshwater enrichments were inoculated with anaerobic digested sludge from the municipal sewage plants in Konstanz and Göttingen, FRG, and with black anaerobic sediment samples from polluted creeks near Hannover and Konstanz, FRG. Marine enrichments were inoculated with anaerobic, black sediment from channels in Venice, Italy. Desulfovibrio vulgaris strain Marburg was kindly provided by R. K. Thauer, Marburg. Methanospirillum hungatei strain Mlh was isolated from digested sludge and uses hydrogen and formate as sole substrates.

\section{Cultivation conditions and chemical analysis}

All procedures for cultivation as well as for analysis of metabolic products were as previously described (Widdel and Pfennig 1981; Schink and Pfennig 1982; Tschech and Schink 1985). The mineral medium for enrichment and further cultivation was carbonate-buffered and sulfide-reduced, and contained trace element solution SL10 (Widdel et al. 1983), selenite-tungstate solution (Tschech and Pfennig 1984) and vitamin-solution (Pfennig 1978). The $\mathrm{pH}$ was 


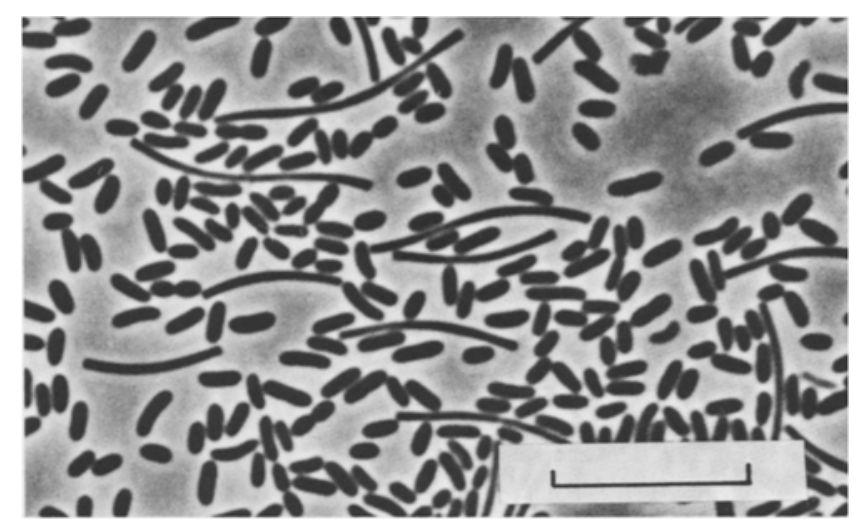

Fig.1. Phase contrast photomicrograph of the defined coculture KN032 with Methanospirillum hungatei degrading 3-hydroxybenzoate. Note the appearance of both straight and slightly curved rods. Bar equals $10 \mu \mathrm{m}$

adjusted to 7.2-7.4. Freshwater medium contained $1.0 \mathrm{~g}$ $\mathrm{NaCl}$ and $0.4 \mathrm{~g} \mathrm{MgCl}_{2} \cdot 6 \mathrm{H}_{2} \mathrm{O}$, salt water medium $20.0 \mathrm{~g}$ $\mathrm{NaCl}$ and $3.0 \mathrm{~g} \mathrm{MgCl}_{2} \cdot 6 \mathrm{H}_{2} \mathrm{O}$ per 1 .

\section{Isolation and characterization}

Defined cultures were obtained by repeated application of the agar shake culture method described by Pfennig (1978). The medium contained the respective benzenoid substrate $(1-5 \mathrm{mM}), 2 \mathrm{mM}$ acetate, $5 \mathrm{mM}$ sulfate and a lawn of $D e-$ sulfovibrio vulgaris or Methanospirillum hungatei. Tubes were gassed with $\mathrm{N}_{2} / \mathrm{CO}_{2}(80 \% / 20 \%)$ gas mixture and sealed with butyl rubber stoppers. Purity of cultures was checked microscopically after growth in defined as well as in complex medium (AC-medium, Difco Laboratories, Detroit, MI, USA). All growth tests were carried out at least in triplicate at $28^{\circ} \mathrm{C}$.

All chemicals were of reagent grade and obtained from E. Merck AG, Darmstadt, FRG, or Fluka, Neu-Ulm, FRG.

\section{Results}

\section{Enrichments with 3-hydroxybenzoate}

Enrichment tubes containing $5 \mathrm{mM}$ 3-hydroxybenzoate (3HB) as sole organic energy and carbon source were inoculated with anaerobic sewage or sediment samples from freshwater or marine habitats. In freshwater enrichment cultures, methane production started after 10 to 14 days, whereas in enrichment cultures with marine sediments, methane production was observed only after 25 days. These marine enrichments grew very slowly furthermore and were not characterized any further. Freshwater enrichment cultures were transferred every 10 to 15 days into fresh culture medium. After five transfers, they degraded 3-HB quantitatively to acetate and methane. In enrichment cultures from both digestd sludge or freshwater creek sediments, the same bacterial population developed. The hydrogen-consuming methanogens resembled Methanospirillum sp. The predominant non-methanogenic bacteria were slightly curved immotile rods. Isolation of these bacteria was tried in coculture with either Desulfovibrio vulgaris or Methanospirillum hungatei as hydrogen scavenger. In agar shake cultures with $M$. hungatei added, many colonies developed up to the last dilution steps but none of them contained

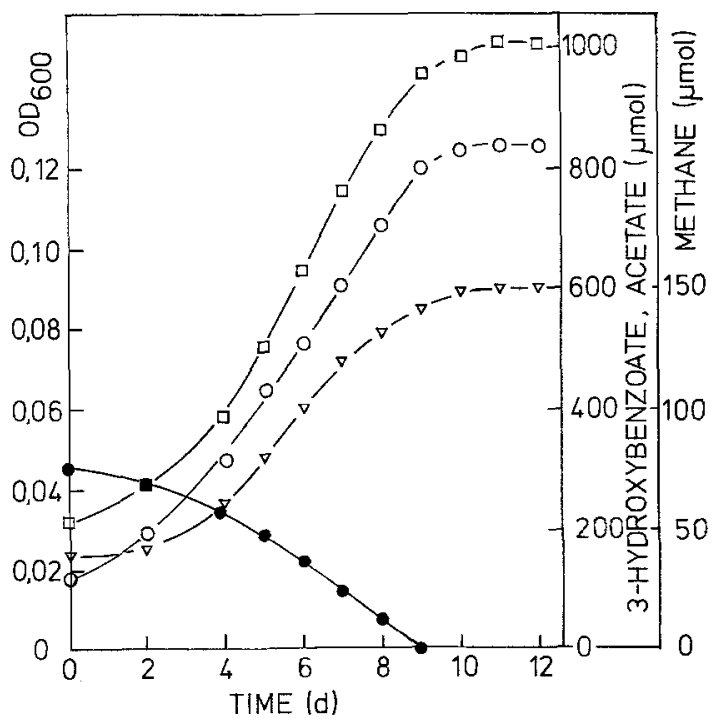

Fig. 2. Fermentation time course of coculture KN032 growing with 3-hydroxybenzoate. Experiments were performed at $28^{\circ} \mathrm{C}$ in $120 \mathrm{ml}$ serum bottles sealed with butyl rubber septa. Samples were taken by syringe at times indicated. The headspace gas was $\mathrm{N}_{2} / \mathrm{CO}_{2}$ $(80 \% / 20 \%)$ gas mixture. $\bigcirc$ Cell density; $\square$ acetate; $\nabla$ methane; 3-hydroxybenzoate

the cell type mentioned. In agar shake cultures with $D$. vulgaris added, fewer colonies developed in the first two weeks. After 4-5 weeks of incubation, lens-shaped yellowish colonies appeared up to the last dilution tube which contained the 3-HB degrading bacterium and $D$. vulgaris. Two colonies were further purified in two subsequent agar dilution series to ascertain purity of the syntrophic coculture; both isolates, strain $\mathrm{KN} 032$ and KN033, were physiologically identical.

\section{Characterization of the 3-hydroxybenzoate degrading strain KN032}

Cells of strain KN032 appeared in two forms, either as straight rods or as slightly curved rods, both with round ends, $0.8 \mu \mathrm{m}$ wide and $1.5-3.0 \mu \mathrm{m}$ long, occurring singly or in pairs (Fig. 1). The Gram reaction was negative. Motility or spore formation was never observed. Cells grew well in mineral salts medium in coculture with $D$. vulgaris. This coculture did not grow without sulfate indicating an obligately syntrophic dependence. When $M$. hungatei - as an active hydrogen scavenger - was added to such a sulfatefree coculture growth recuperated. After some transfers of this methanogenic coculture into fresh sulfate-free medium only few cells of the sulfate-reducer were still present, but this low number of $D$. vulgaris cells remained nearly constant over more than 20 following transfers. Even from such a well-growing methanogenic coculture it was not possible to isolate the 3-HB degrading bacterium in coculture with $M$. hungatei because in agar shake cultures colonies did never develop. Therefore, always few cells of $D$. vulgaris remained in methanogenic cocultures. Addition of $\mathrm{NaCl}\left(10 \mathrm{~g} \cdot \mathrm{l}^{-1}\right)$ and $\mathrm{MgCl}_{2} \cdot 6 \mathrm{H}_{2} \mathrm{O}\left(1.5 \mathrm{~g} \cdot \mathrm{1}^{-1}\right)$, decreased both growth rate and growth yield, and no growth at all occurred in salt water medium. Phosphate concentrations higher than $5 \mathrm{mM}$ inhibited growth. Yeast extract was not required and had no influence on growth rate or yield at $0.5 \mathrm{~g} \cdot 1^{-1}$ concentration. Growth was optimal at $28^{\circ} \mathrm{C}$ and was possible between $25^{\circ} \mathrm{C}$ 
Table 1. Growth yiclds and stoichiometry of fermentation of the defined coculture KN032

\begin{tabular}{|c|c|c|c|c|c|c|c|c|}
\hline \multirow[t]{2}{*}{ Substrate } & \multirow{2}{*}{$\begin{array}{l}\text { Amount of } \\
\text { substrate } \\
\text { provided } \\
(\mu \mathrm{mol})\end{array}$} & \multirow[t]{2}{*}{ O.D. 600} & \multirow{2}{*}{$\begin{array}{l}\text { Cell dry } \\
\text { weight } \\
\text { formed }^{\mathrm{a}} \\
(\mathrm{mg})\end{array}$} & \multirow{2}{*}{$\begin{array}{l}\text { Substrate } \\
\text { assimilated }^{\mathbf{b}} \\
(\mu \mathrm{mol})\end{array}$} & \multicolumn{2}{|c|}{$\begin{array}{l}\text { Products formed } \\
\text { ( } \mu \mathrm{mol})\end{array}$} & \multirow{2}{*}{$\begin{array}{l}\text { Molar yield } \\
\text { (g dry cell } \\
\text { material } \\
\text { per mol } \\
\text { substrate) }\end{array}$} & \multirow{2}{*}{$\begin{array}{l}\text { Recovery of } \\
\text { electrons } \\
(\%)\end{array}$} \\
\hline & & & & & Acetate & Methane & & \\
\hline Benzoate & $\begin{array}{l}250 \\
375\end{array}$ & $\begin{array}{l}0.10 \\
0.13\end{array}$ & $\begin{array}{l}1.44 \\
1.87\end{array}$ & $\begin{array}{r}7.9 \\
10.3\end{array}$ & $\begin{array}{r}683 \\
1050\end{array}$ & $\begin{array}{l}174 \\
269\end{array}$ & $\begin{array}{l}5.8 \\
5.0\end{array}$ & $\begin{array}{l}94.4 \\
96.4\end{array}$ \\
\hline 3-Hydroxybenzoate & $\begin{array}{l}250 \\
375\end{array}$ & $\begin{array}{l}0.15 \\
0.20\end{array}$ & $\begin{array}{l}2.16 \\
2.88\end{array}$ & $\begin{array}{l}12.7 \\
17.0\end{array}$ & $\begin{array}{r}671 \\
1015\end{array}$ & $\begin{array}{l}118 \\
166\end{array}$ & $\begin{array}{l}8.6 \\
7.7\end{array}$ & $\begin{array}{l}95.1 \\
94.3\end{array}$ \\
\hline
\end{tabular}

a Cell dry weights were determined directly with cells grown in $500 \mathrm{ml}$ cultures on 3 -HB. Other dry weight values were calculated by comparison of cell densities reached in $120 \mathrm{ml}$ serum bottles. The conversion factor used was $0.1 \mathrm{O}$. D. $\cong 28.8 \mathrm{mg}$ cell dry matter per 1

${ }^{b}$ Assimilation of benzoate or $3-\mathrm{HB}$ for cell material was calculated by the equations: $17 \mathrm{C}_{7} \mathrm{H}_{6} \mathrm{O}_{2}+\mathrm{CO}_{2}+54 \mathrm{H}_{2} \mathrm{O} \rightarrow 30\left[\mathrm{C}_{4} \mathrm{H}_{7} \mathrm{O}_{3}\right]$ thus $5.5 \mu \mathrm{mol}$ benzoate corresponds to $1 \mathrm{mg}$ of cell dry matter. $17 \mathrm{C}_{7} \mathrm{H}_{6} \mathrm{O}_{3}+47 \mathrm{H}_{2} \mathrm{O} \rightarrow 28\left[\mathrm{C}_{4} \mathrm{H}_{7} \mathrm{O}_{3}\right]+7 \mathrm{CO}_{2}$; thus $5.9 \mu$ mol hydroxybenzoate is required to form $1 \mathrm{mg}$ of cell dry matter. All figures are means of at least three independent assays

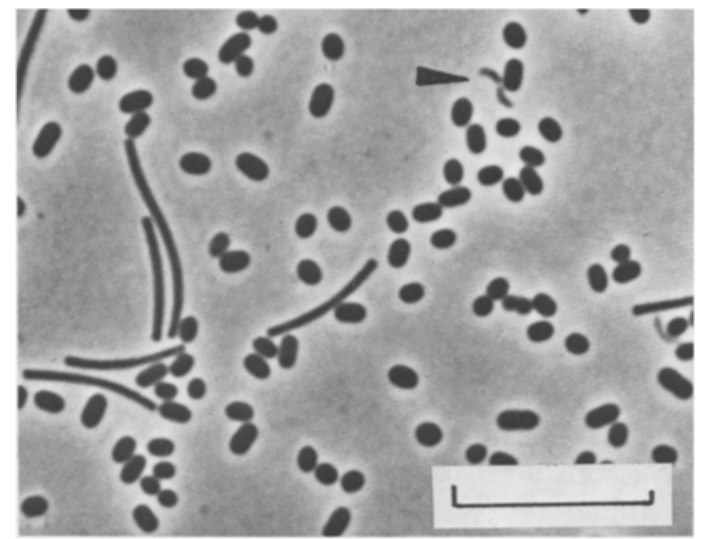

Fig. 3. Phase contrast photomicrograph of the defined coculture Wo021 with Methanospirillum hungatei degrading salicylate. Arrow points at cells of Desulfovibrio vulgaris. Bar equals $10 \mu \mathrm{m}$

and $34^{\circ} \mathrm{C}$. The $\mathrm{pH}$ limits were 6.4 and 7.4 with optimal growth at $\mathrm{pH}$ 7.1. Tests for degradation of various substrates and for determination of $\mathrm{pH}$ and temperature limits were performed with the sulfate-reducing coculture. The doubling time during growth with $3-\mathrm{HB}$ was $3.0 \pm 0.5$ days, irrespective of whether the hydrogen-scavenging bacterium was a sulfate reducer or a methanogen. Growth with benzoate was slower (doubling time $4.0 \pm 0.5$ days). Lag-phases after inoculation of fresh medium varied from 0.5 to 5 days. A time course of substrate degradation and product formation during growth with 3-HB under optimal conditions is presented in Fig. 2 . The only substrates utilized by the new isolate were 3-hydroxybenzoate and benzoate. Other aromatic compounds were not degraded, and no qualitative modification of the UV-absorption spectra of the culture fluids was observed after 6 weeks of incubation. The following substrates were tested for degradation: resorcinol, phloroglucinol, pyrogallol, 2,4-, $2,6-$ and $3,5-$ dihydroxybenzoate, gallate, 3-aminobenzoate, cinnamate, caffeate, 3-phenylpropionate (each provided at $5 \mathrm{mM}$ concentration); phenol, 4-hydroxybenzoate, 2hydroxybenzoate (salicylate), 3-methoxybenzoate, 3-coumarate, catechol, hydroquinone, 2,3-, 2,5- and 3,4dihydroxybenzoate, phenylacetate (each provided at $2.5 \mathrm{mM}$ concentration). Cyclohexanecarboxylate, cyclohexanone, cyclohexanol, pimelate, adipate, heptanoate, caproate, valerate, butyrate, 3-hydroxybutyrate, crotonate, malate, succinate, fumarate, pyruvate, citrate, glucose, fructose, arabinose, glycerol, methanol or ethanol were not fermented (concentrations were 2 or $5 \mathrm{mM}$ ). Neither fumarate nor sulfate, thiosulfate, sulfite, sulfur or nitrate was reduced by the 3-HB degrading bacterium. Cultures growing with 3-HB were not inhibited by addition of $1 \mathrm{mM} 2-, 3-$ or 4-chlorobenzoate. Degradation of these compounds could not be detected either even after 10 weeks of incubation.

Substrate fermentation was always quantitative according to the following fermentation equations (Table 1): Benzoate:

$$
\begin{aligned}
4 \mathrm{C}_{6} \mathrm{H}_{5} \mathrm{COO}^{-} & +19 \mathrm{H}_{2} \mathrm{O} \\
& \rightarrow 12 \mathrm{CH}_{3} \mathrm{COO}^{-}+9 \mathrm{H}^{+}+\mathrm{HCO}_{3}^{-}+3 \mathrm{CH}_{4}
\end{aligned}
$$

Hydroxybenzoate:

$$
\begin{aligned}
2 \mathrm{C}_{6} \mathrm{H}_{4}(\mathrm{OH}) \mathrm{COO}^{-} & +9 \mathrm{H}_{2} \mathrm{O} \\
& \rightarrow 6 \mathrm{CH}_{3} \mathrm{COO}^{-}+5 \mathrm{H}^{+}+\mathrm{HCO}_{3}^{-}+\mathrm{CH}_{4}
\end{aligned}
$$

Growth yields with 3-HB were higher than those with benzoate (Table 1), and less methane was formed during growth with 3-HB than with benzoate. Degradation of 3-HB was possible also with Acetobacterium woodii as hydrogen scavenger resulting in complete substrate conversion to acetate. Such a homoacetogenic fermentation was not possible with benzoate as substrate.

When 3-HB degrading methanogenic cultures were inhibited by addition of $0.5 \mathrm{mM} 2$-bromoethanesulfonate, no methane was formed but 3-HB added to a concentration of $5 \mathrm{mM}$ was dehydroxylated to benzoate completely within 5 days. In dense cell suspensions of sulfate reducing cocultures $(\mathrm{OD} \approx 14.0$ ) dehydroxylation of $15 \mathrm{mM} 3-\mathrm{HB}$ occurred within 1 day if sulfate was omitted.

\section{Enrichments with 2-hydroxybenzoate (salicylate)}

Enrichment cultures with $2.5 \mathrm{mM}$ 2-hydroxybenzoate (2HB; salicylate) as sole energy and carbon source were inoculated with anaerobic sewage sludge or sediments from freshwater or marine habitats. In enrichments with marine sediment, 2-HB was not degraded even after 4 months of incubation. In freshwater medium, $2.5 \mathrm{mM} 2-\mathrm{HB}$ was mineralized completely to methane and $\mathrm{CO}_{2}$ within 5 to 6 weeks. Acetate accumulated as an intermediate to a maximal concentration of $3 \mathrm{mM}$. From sewage sludge and sediments, the same immotile short coccoid rod was enriched which 
Table 2. Growth yields and stoichiometry of fermentation of the defined coculture Wo021

\begin{tabular}{|c|c|c|c|c|c|c|c|c|}
\hline \multirow[t]{2}{*}{ Substrate } & \multirow{2}{*}{$\begin{array}{l}\text { Amount of } \\
\text { substrate } \\
\text { provided } \\
(\mu \mathrm{mol})\end{array}$} & \multirow[t]{2}{*}{ O.D. 600} & \multirow{2}{*}{$\begin{array}{l}\text { Cell dry } \\
\text { weight } \\
\text { formed } \\
\text { (mg) }\end{array}$} & \multirow{2}{*}{$\begin{array}{l}\text { Substrate } \\
\text { assimilated } \\
(\mu \mathrm{mol})\end{array}$} & \multicolumn{2}{|c|}{$\begin{array}{l}\text { Products formed } \\
\text { ( } \mu \mathrm{mol})\end{array}$} & \multirow{2}{*}{$\begin{array}{l}\text { Molar yield } \\
\text { (g dry cell } \\
\text { material } \\
\text { per mol } \\
\text { substrate) }\end{array}$} & \multirow{2}{*}{$\begin{array}{l}\text { Recovery } \\
\text { of electrons } \\
(\%)\end{array}$} \\
\hline & & & & & Acetate & Methane & & \\
\hline Benzoate & 250 & 0.11 & 1.54 & 8.5 & 694 & 172 & 6.2 & 95.6 \\
\hline Salicylate & 125 & 0.07 & 0.98 & 5.8 & 345 & 61 & 7.8 & 97.3 \\
\hline 3-Hydroxybenzoate & 250 & 0.15 & 2.10 & 12.4 & 675 & 117 & 8.4 & 95.3 \\
\hline
\end{tabular}

All procedures for determination of cell dry weights and assimilated substrate were the same as described in Table 1; for strain Wo021 the conversion factor used was 0.1 O.D. $\hat{=} 28.0 \mathrm{mg}$ cell dry matter per 1 . All figures are means of at least three independent assays

obviously degraded salicylate. The other prevailing bacteria present were similar to Methanospirillum hungatei and Methanothrix soehngenii. In agar dilution series, little whitish, lens-shaped colonies appeared after 6 weeks of incubation. These colonies contained the coccoid salicylate degrader, Desulfovibrio vulgaris, and many very thin, long motile cells resembling spirochetes. These spirochetes were motile in the agar-medium: during the first 2 weeks of incubation one could observe spherical, spreading colonies. The center only contained few cells; cells swarmed away from the center obviously following a nutrient gradient. After almost 3 weeks of incubation no such colonies could be detected anymore because the spirochetes were homogenously distributed in the agar medium. Four successive shake series were necessary to dilute out the spirochetes and to isolate the salicylate degrader in defined coculture with $D$. vulgaris.

\section{Characterization of the salicylate-degrading strain Wo021}

Cells of strain Wo021 were very short, coccoid rods with round ends, $0.8-1.7 \mu \mathrm{m}$ long and $0.8-0.9 \mu \mathrm{m}$ wide, occurring singly or in pairs (Fig. 3). The Gram reaction was negative. Motility was never observed, and spores were not detected. Cells grew well in mineral medium in coculture with $D$. vulgaris; this coculture did not grow in the absence of sulfate, indicating obligate dependency of the salicylate degrader on interspecies hydrogen transfer. $M$. hungatei or $A$. woodii could also serve as syntrophic hydrogen oxidizers when sulfate was omitted. As in agar shake cultures with the methanogen or the acetogen added as hydrogen scavenger colonies did never develop, a few cells of $D$. vulgaris were always present in methanogenic or acetogenic cocultures (Fig. 3). Addition of $\mathrm{NaCl}$ and $\mathrm{MgCl}_{2}$ to the freshwater medium decreased the growth rate, and no growth occurred in seawater medium. Addition of yeast extract was never necessary. With sulfate-reducing cocultures, the optimal growth conditions were at $28^{\circ} \mathrm{C}$ and $\mathrm{pH} 7.2$. Besides salicylate, the new isolate also degraded 3-HB and benzoate in coculture with hydrogen-oxidizing anaerobes. Doubling times were about 3.5 days with $3-\mathrm{HB}, 4.5$ days with benzoate, and 5.5 days with salicylate as substrate. The molar growth yields obtained by strain Wo021 with 3-HB or benzoate were nearly the same as those obtained with strain KN032. Yields with salicylate were similar to those with 3-HB (Table 2). No further substrate was used by strain Wo021, neither 2-aminobenzoate (anthranilate) nor any of those compounds tested with strain KN032 (see foregoing chapter). Addition of $0.5 \mathrm{mM} \mathrm{2-,3-}$ or 4-chlorobenzoate inhibited growth of strain Wo021 completely. External electron acceptors were not reduced.

Substrate utilization was always quantitative according to the fermentation equations given in the foregoing chapter. With dense cell suspensions of sulfate reducing or methanogenic cocultures, dehydroxylation of $3-\mathrm{HB}$ to benzoate could be demonstrated by inhibition of the hydrogen oxidizer. Degradation of salicylate was blocked completely when interspecies hydrogen transfer was inhibited: The concentration of salicylate remained unchanged even after 10 days of incubation of the inhibited coculture.

\section{Enrichments with 4-hydroxybenzoate}

Enrichments with $2.5 \mathrm{mM}$ 4-hydroxybenzoate (4-HB) as sole energy and carbon source were inoculated with sewage or sediment samples from freshwater or marine habitats. In freshwater enrichment cultures, methane production from 4-HB degradation started after almost 7 weeks. Lowering the substrate concentration to $1 \mathrm{mM}$ shortened the lagphases of freshly transferred cultures; nevertheless, fresh transfer cultures always required high inocula to avoid long lag phases. After 10 transfers the cultures respresented a stable mixed culture consisting mainly of three types of bacteria. These were Gram-negative, immotile, nonsporing rods with round ends, $0.75-1.0 \mu \mathrm{m}$ wide and $1.0-2.0 \mu \mathrm{m}$ long, together with hydrogen-oxidizing bacteria resembling Methanospirillum sp. and acetate-degrading methanogens resembling Methanothrix soehngenii (Fig. 4a). 4-HB degradation to methane and $\mathrm{CO}_{2}$ was always complete (Table 3), with acetate accumulating intermediately up to $2 \mathrm{mM}$. The generation times of well-growing enrichment cultures were nearly 6 days. In enrichments from marine sediments, 4-HB degradation started after $6-7$ weeks and growth of these cultures was slow compared to that of the enrichments from freshwater habitats. In the marine cultures, big, refractile, slowly motile, non-sporing rods, $1.4-1.5 \mu \mathrm{m} \times 1.5-3.5 \mu \mathrm{m}$ in size, (Fig. 4 b) prevailed which probably degraded the aromatic substrate to acetate and hydrogen. These were further metabolized by methanogens (Table 3 ).

In all enrichment cultures from freshwater as well as from marine habitats, 4-HB was completely decarboxylated to phenol within 1 day. The further degradation of phenol took several weeks. 4-HB was decarboxylated even if applied at $10 \mathrm{mM}$ concentration but the resulting $10 \mathrm{mM}$ phenol inhibited any further microbial activity. 3,4-Dihydroxybenzoate (protocatechuate) was decarboxylated within 1 day by all enrichment cultures as well; the resulting catechol was not degraded. 2,4-Dihydroxybenzoate was not 


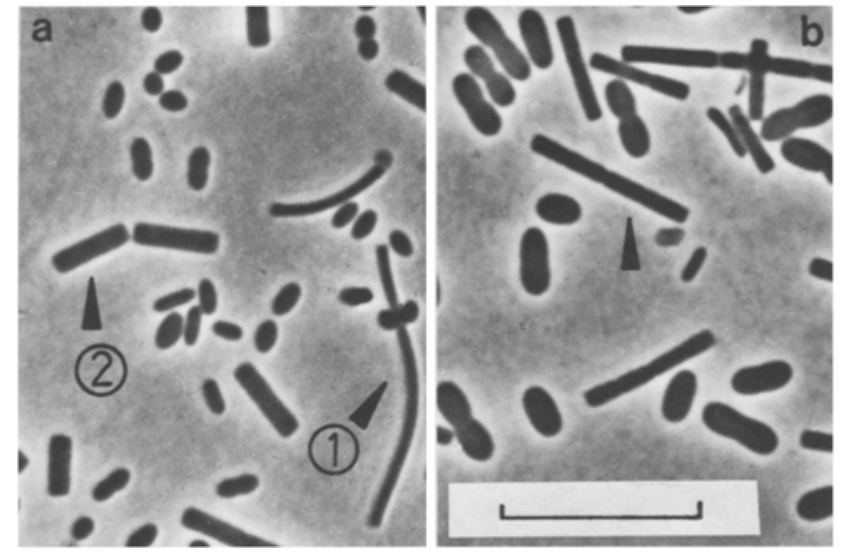

Fig. 4a, b. Phase contrast photomicrographs of cultures enriched with 4-hydroxybenzoate. a Enrichment culture KNPOB from a freshwater habitat; arrow $l$ points at cells resembling Methanospirillum sp., arrow 2 at cells resembling Methanothrix soehngenii; $\mathbf{b}$ enrichment culture MaPOB from marine sediment, arrow points at cells resembling $M$. soehngenii. Bar equals $10 \mu \mathrm{m}$ for both prints

Table 3. Stoichiometry of 4-hydroxybenzoate degradation by enrichment cultures KNPOB or MaPOB. Tests were performed at $28^{\circ} \mathrm{C}$ in $120 \mathrm{ml}$ serum bottles containing $50 \mathrm{ml}$ mineral salts medium under $\mathrm{N}_{2} / \mathrm{CO}_{2}(80 \% / 20 \%)$ gas mixture. 4-Hydroxybenzoate was fed repeatedly at $1 \mathrm{mM}$ concentration when the substrate concentration was lower than $0.1 \mathrm{mM}$

\begin{tabular}{lllll}
\hline & $\begin{array}{l}\text { Amount of } \\
\text { substrate } \\
\text { provided } \\
(\mu \mathrm{mol})\end{array}$ & $\begin{array}{l}\text { Cell density } \\
\text { reached } \\
\text { O.D.600 }\end{array}$ & $\begin{array}{l}\text { Methane } \\
\text { formed } \\
(\mu \mathrm{mol})\end{array}$ & $\begin{array}{l}\text { Recovery of } \\
\text { reducing } \\
\text { equivalents } \\
(\%)\end{array}$ \\
\hline KNPOB & 50 & 0.04 & 161 & 92.0 \\
& 100 & 0.09 & 326 & 93.1 \\
& 250 & 0.20 & 818 & 93.5 \\
MaPOB & 50 & 0.04 & 165 & 94.3 \\
& 100 & 0.08 & 318 & 90.9 \\
& 250 & 0.19 & 811 & 92.7 \\
\hline
\end{tabular}

${ }^{\text {a }}$ Reducing equivalents recovered as methane; reducing equivalents used for cell synthesis are not considered

decarboxylated by any of the cultures. After subculturing the 4-HB-enrichment cultures four times with phenol as substrate, these cultures had lost the ability to decarboxylate 4-HB or 3,4-dihydroxybenzoate; bacteria specialized for decarboxylation may have been outdiluted. The 4-HB- or phenol-degrading bacteria were not isolated in defined cocultures.

\section{Discussion}

In the present paper, new strains of strictly anaerobic bacteria are described which were enriched and isolated with 3or 2-hydroxybenzoate (salicylate). The strains obtained with 3-HB only degraded this substrate and benzoate; the isolate from enrichments with 2-HB catabolised 2-HB, 3-HB, and benzoate. No other substrates were attacked, and no acceptors other than protons were reduced. Enrichment cultures with 4-HB could not be worked up to a defined culture. However, the 4-HB-fermenting bacteria in these enrichments were obviously different from the two types obtained with 2-HB and 3-HB. It appears that all these anaerobes involved in the fermentative degradation of monohydroxybenzoates are very specialized organisms with a quite restricted substrate range. It is difficult to imagine how these bacteria survive in a natural anoxic environment in which these hydroxybenzoates do not represent a major substrate source (Pridham 1965). Defined syntrophic mixed cultures enriched and isolated with benzoate or 3chlorobenzoate do not attack hydroxybenzoates at all (Mountfort and Bryant 1982; Shelton and Tiedje 1984).

The new isolates were all Gram-negative rods, and depended for substrate degradation on a syntrophic cooperation with hydrogen-oxidizing anaerobes. Conversions of benzoate [Eq. (1)] and hydroxybenzoate [Eq. (2)] to acetate, $\mathrm{CO}_{2}$, and hydrogen are both endergonic reactions under standard conditions (calculations after Thauer et al. 1977; Kaiser and Hanselmann 1982; Thauer and Morris 1984):

$$
\begin{aligned}
& \mathrm{C}_{6} \mathrm{H}_{5} \mathrm{COO}^{-}+7 \mathrm{H}_{2} \mathrm{O} \rightarrow \\
& 3 \mathrm{CH}_{3} \mathrm{COO}^{-}+3 \mathrm{H}^{+}+\mathrm{HCO}_{3}^{-}+3 \mathrm{H}_{2} \\
& \Delta \mathrm{G}_{\mathrm{o}}^{\prime}=+57.9 \mathrm{~kJ} \\
& \mathrm{C}_{6} \mathrm{H}_{4}(\mathrm{OH}) \mathrm{COO}^{-}+6 \mathrm{H}_{2} \mathrm{O} \rightarrow \\
& 3 \mathrm{CH}_{3} \mathrm{COO}^{-}+3 \mathrm{H}^{+}+\mathrm{HCO}_{3}^{-}+2 \mathrm{H}_{2} \\
& \Delta \mathrm{G}_{\mathrm{o}}^{\prime}=+6.6 \mathrm{~kJ}
\end{aligned}
$$

In both cases, removal of one fermentation product, e.g. hydrogen, is necessary to make the fermentation possible. If hydrogen is oxidized by a homoacetogenic anaerobe [Eq. (3)], the overall free energy change for hydroxybenzoate degradation is $-46.9 \mathrm{~kJ}$ per mol [Eqs. (2 and 3)] but only $-20.6 \mathrm{~kJ}$ per mol for benzoate degradation [Eqs. (1 and 3)]. Apparently, this amount of free energy available is too small to feed two partner organisms; benzoate degradation could only be combined with methanogenic hydrogen oxidation [Eq. (4)], therefore $\left[\Delta \mathrm{G}_{\mathrm{o}}^{\prime}=-43.8 \mathrm{~kJ}\right.$ per mol benzoate, Eqs. (1) and (4)]

$$
\begin{gathered}
4 \mathrm{H}_{2}+2 \mathrm{HCO}_{3}^{-}+\mathrm{H}^{+} \rightarrow \\
\mathrm{CH}_{3} \mathrm{COO}^{-}+4 \mathrm{H}_{2} \mathrm{O} \\
\Delta \mathrm{G}_{\mathrm{o}}^{\prime}=-104.5 \mathrm{~kJ} \\
4 \mathrm{H}_{2}+\mathrm{HCO}_{3}^{-}+\mathrm{H}^{+} \rightarrow \mathrm{CH}_{4}+3 \mathrm{H}_{2} \mathrm{O} \\
\Delta \mathrm{G}_{\mathrm{o}}^{\prime}=-135.6 \mathrm{~kJ}
\end{gathered}
$$

On the basis of these considerations, it is understandable that we could observe fermentation of hydroxybenzoates in both methanogenic and homoacetogenic cocultures whereas benzoate oxidation was only obtained in the methanogenic cocultures. The free energy changes for substrate oxidation in combination with hydrogen-oxidizing sulfate reducers are slightly higher than those calculated for the methanogenic cocultures.

The defined cocultures described in this paper converted 3-HB to benzoate which accumulated in the medium if further oxidation was inhibited by either bromoethanesulfonate or lack of sulfate. No such conversion was observed with 2-HB. On the basis of these results, a hypothetical scheme can be suggested which combines the degradation pathways of these substrates (Fig. 5; modified after Dutton and Evans 1969; Evans 1977). According to this scheme, 3 -HB is converted to benzoate via reductive dehydroxylation. 2-HB enters the benzoate degradation pathway at a later stage when a hydroxy function in ortho-position is of advantage for the ring cleavage and further oxidation process which leads to three acetate residues and one $\mathrm{CO}_{2}$. This 
<smiles>O=C(O)c1cccc(O)c1</smiles>

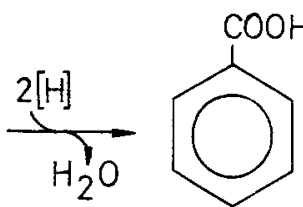<smiles>CC(C)CC(=O)SS</smiles><smiles>CO</smiles><smiles>O=C(O)c1ccccc1O</smiles>

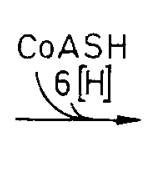<smiles>O=C(O)C1CCCCC1O</smiles>

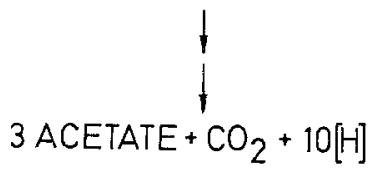

Fig. 5. Hypothetical pathway of anaerobic degradation of benzoate, 2- and 3-hydroxybenzoate. Explanations in the text

scheme postulates a nearly identical pathway of 3-HB and benzoate degradation which should provide the same chances for substrate-linked phosphorylation with both substrates. However, the cell yields obtained with these two substrates differed considerably by about $50 \%$. This finding can be explained in two ways: Either 3-HB degradation provides a further possibility of ATP synthesis by e.g. electron transport or other energy-conserving transport processes, or part of the energy conserved in benzoate degradation by substrate-linked phosphorylation has to be reinvested into energy-consuming reactions.

The first hypothesis is in accordance with the observation that reductive elimination of a ring substituent, in this case, removal of chlorine from 3-chlorobenzoate, can provide enough energy for an anaerobic bacterium specialized in this reaction to cover all its energy needs (Shelton and Tiedje 1984). A similar process was assumed to be involved in reductive dehydroxylation of catechol and hydroquinone to phenol. The redox potential of these redox couples was calculated to be in the range of -50 to $-100 \mathrm{mV}$ (Szewzyk et al. 1985). Electrons at the redox potential of free hydrogen or NADH could be transported to this potential with concomitant ATP synthesis. It was shown recently that an Enterobacter cloacae strain can combine the oxidation of the methyl residue of ferulate with the reductive dehydroxylation of the resulting caffeate and its further reduction to phenylpropionate (Grbić-Galić and LaPat-Polasko 1985). One could also think of a special uptake system for 3-HB (which is more polar than benzoate) into the cell that could be coupled with an ion antiport which allows additional ATP synthesis by a suitable membrane-bound ATPase.

The second hypothesis is based on the consideration that some of the electrons gained during benzoate oxidation to acetate arise from desaturation reactions at the redox potential of about $0 \mathrm{mV}$. Release of these electrons as molecular hydrogen $\left(E_{o}^{\prime}=-420 \mathrm{mV}\right)$ would require energy for a hypothetical reversed electron transport (Thauer and Morris 1984). First experimental evidence for the existence of such an anaerobic reversed electron transport was obtained recently with the succinate dehydrogenase system of acetateoxidizing sulfur-reducing bacteria (Paulsen et al. 1986). If some of these electrons could be transferred at about the same potential to a reductive dehydroxylation reaction (as with 3-HB) or would not arise at all (because the substrate is already hydroxylated in a suitable poisition - as with 2-HB), the cell could save some of the energy which otherwise would need to be invested into an energy-consuming reversed electron transport.

The different pathways of 2-HB and 3-HB degradation again follow the rule already found with degradation of the dihydroxybenzenes (Szewzyk et al. 1985; Tschech and Schink 1985): Hydroxy groups in a position suitable for $\beta$-oxidation of the ring skeleton are conserved whereas those which would impede $\beta$-oxidation are reductively eliminated prior to ring saturation. A third way of substrate modification was observed in the present study with 4-HB degradation: In all enrichment cultures with this substrate, 4-HB was first decarboxylated to phenol before the ring system was further modified. Similar decarboxylation reactions were observed with other hydroxybenzoates, e. g. gallic acid or 2,4,6-trihydroxybenzoate (Schink and Pfennig 1982; Samain et al. 1986) and with two resorcylic acids (Tschech and Schink 1985). Thus, it depends on the relative position of the substituents to each other whether a hydroxybenzoate is degraded via benzoate or via phenol or, as with $2-\mathrm{HB}$, retains both functional groups until ring cleavage.

Acknowledgements. The authors are indebted to Prof. Dr. N. Pfennig for support and stimulating discussions. This work was supported by a grant of the Deutsche Forschungsgemeinschaft.

\section{References}

Dutton PL, Evans WC (1969) The metabolism of aromatic compounds by Rhodopseudomonas palustris. A new, reductive, method of aromatic ring metabolism. Biochem J 113:525-536

Evans WC (1977) Biochemistry of the bacterial catabolism of aromatic compounds in anaerobic environments. Nature (Lond) $270: 17-22$

Grbić-Galić D, La Pat-Polasko L (1985) Enterobacter cloacae DG6: a strain that transforms methoxylated aromatics under aerobic and anaerobic conditions. Current Microbiol 12: $321-324$

Healy JB, Young LY (1979) Anaerobic biodegradation of eleven aromatic compounds to methane. Appl Environ Microbiol $38: 84-89$

Kaiser JP, Hanselmann KW (1982) Fermentative metabolism of substituted monoaromatic compounds by a bacterial community from anaerobic sediments. Arch Microbiol 133:185194

Mountfort DO, Bryant MP (1982) Isolation and characterization of an anaerobic syntrophic benzoate-degrading bacterium from sewage sludge. Arch Microbiol 133:249-256

Mountfort DO, Brulla WJ, Krumholz LR, Bryant MP (1984) Syntrophus buswellii gen. nov., sp. nov: : a benzoate catabolizer from methanogenic ecosystems. Int J Syst Bacteriol 34:216217

Paulsen J, Kröger A, Thauer RK (1986) ATP-driven succinate oxidation in the catabolism of Desulfuromonas acetoxidans. Arch Microbiol 144:78-83

Pfennig N (1978) Rhodocyclus purpureus gen. nov. and sp. nov., a ring-shaped, vitamin $B_{12}$-requiring member of the family Rhodospirillaceae. Int J Syst Bacteriol 28:283-288

Pridham JB (1965) Low molecular weight phenols in higher plants. Ann Rev Plant Physiol 6:13-36

Samain E, Albagnac G, Dubourguier HC (1986) Initial steps of catabolism of trihydroxybenzenes in Pelobacter acidigallici. Arch Microbiol 144:242-244 
Schink B, Pfennig N (1982) Fermentation of trihydroxybenzenes by Pelobacter acidigallici gen. nov. sp. nov, a new strictly anaerobic, non-sporeforming bacterium. Arch Microbiol 133: $195-201$

Shelton DR, Tiedje JM (1984) Isolation and partial characterization of bacteria in an anaerobic consortium that mineralizes 3-chlorobenzoic acid. Appl Environ Microbiol 48:840-848

Szewzyk U, Szewzyk R, Schink B (1985) Methanogenic degradation of hydroquinone and catechol via reductive dehydroxylation to phenol. FEMS Microbiol Ecol 31:79-87

Tarvin D, Buswell AM (1934) The methane fermentation of organic acids and carbohydrates. J Am Chem Soc 56:1751-1755

Thauer RK, Morris JG (1984) Metabolism of chemotrophic anaerobes: old views and new aspects. In: Kelly DP, Carr NG (eds). The microbe, part II, Prokaryotes and eucaryotes. Society for general microbiology symposium 36 . Cambridge University Press, Cambridge pp 123-168

Thauer RK, Jungermann K, Decker K (1977) Energy conservation in chemotrophic anaerobic bacteria. Bacteriol Rev $41: 100-$ 180

Tschech A, Pfennig N (1984) Growth yield increase linked to caffeate reduction in Acetobacterium woodii. Arch Microbiol 137:163-167
Tschech A, Schink B (1985) Fermentative degradation of resorcinol and resorcylic acids. Arch Microbiol 143:52 - 59

Widdel F, Pfennig N (1981) Studies on dissimilatory sulfate-reducing bacteria that decompose fatty acids. I. Isolation of new sulfate-reducing bacteria enriched with acetate from saline environments. Description of Desulfobacter postgatei gen. nov., sp. nov. Arch Microbiol 129:395-400

Widdel F, Kohring GW, Mayer F (1983) Studies on dissimilatory sulfate-reducing bacteria that decompose fatty acids. III. Characterization of the filamentous gliding Desulfonema limicola gen. nov. sp. nov., and Desulfonema magnum sp. nov. Arch Microbiol 134:286-294

Young LY (1984) Anaerobic degradation of aromatic compounds. In: Gibson DT (ed), Microbial degradation of organic compounds. Marcel Dekker Inc., New York Basel, pp $487-$ 523

Received April 25, 1986/Accepted July 8, 1986 